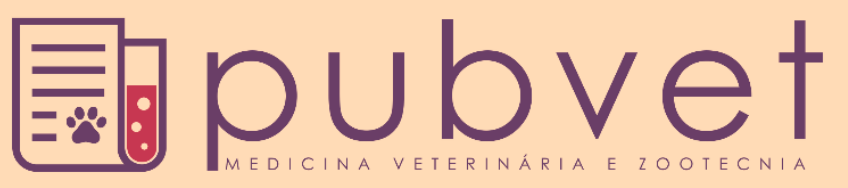

https://doi.org/10.31533/pubvet.v15n05a808.1-7

\title{
Mucinose cutânea em um cão da raça Shar pei: Relato de caso
}

\author{
Bruna Umbria ${ }^{1 * \bullet}$, Juliana Luft², Thayana Krull² \\ ${ }^{1}$ Aprimorando em Clínica Médica de Pequenos Animais do Programa de Aprimoramento Profissional da Universidade Tuiuti do Paraná, \\ Departamento de Medicina Veterinária. Curitiba -PR Brasil. * Autor para correspondência, E-mail: bru.umbria@gmail.com \\ ${ }^{2}$ Discente do Curso de Medicina Veterinária da Universidade Tuiuti do Paraná, Departamento de Medicina Veterinária. Curitiba-PR Brasil.
}

Resumo. A mucinose cutânea é uma dermatopatia idiopática primária que ocorre em cães da raça Shar pei, caracterizada pela excessiva deposição de mucina na derme que leva a apresentação de dobras cutâneas, e em casos mais graves a formação de vesículas ou bolhas. O ácido hialurônico foi identificado como o principal componente da mucina, contudo a etiopatogenia, prevenção e tratamento desta enfermidade ainda não foram totalmente elucidados. Este trabalho relata um cão da raça Shar pei com três anos de idade, diagnosticado com mucinose cutânea. Ao exame físico foram observadas múltiplas vesículas contendo fluido transparente e viscoso e hipotricose em região ventral do pescoço, axilas, flanco bilateral, perianal e na porção distal dos membros. Nos membros pélvicos havia também a presença de edema. A pele acometida apresentava-se inchada, espessada e negativa ao sinal de Godet. Foram realizados exame de sangue, raspado e citologia de pele. Os exames de sangue não apresentaram alterações significativas, assim como o raspado e a citologia de pele apresentaram resultados negativos. Mediante estes resultados optou-se por realizar biópsia de pele e análise histopatológica. Foi observado edema mixomatoso intenso e difuso, principalmente na região mais superficial e perianexal, com formação de lagos de mucina, confirmando o diagnóstico. Para o tratamento foi prescrito prednisolona na dose de $1 \mathrm{mg} / \mathrm{kg}$ a cada 24 horas, durante 7 dias, reduzindo a dose até a suspensão do medicamento em 30 dias. Após 21 dias de tratamento o paciente apresentou resolução total das lesões e do prurido. Foi possível concluir que a mucinose cutânea é uma dermatopatia exclusiva de cães da raça Shar pei devido à intensa seleção genética ao longo da história da raça. O impacto da alta síntese do ácido hialurônico no fenótipo destes cães é apenas parcialmente conhecido. Deste modo, muitos outros locais e efeitos sistêmicos do ácido hialurônico ainda precisam ser compreendidos já que este glicosaminoglicano é sintetizado por diversas células e pode ser encontrado em vários tecidos e fluidos corporais com concentrações variadas.

Palavras-chave: Ácido hialurônico, cães, dermatopatia, mucina

\section{Cutaneous mucinosis in a Shar pei dog: Case report}

Abstract. Cutaneous mucinosis is a primary idiopathic dermatopathy that occurs in dogs of the Shar pei breed, characterized by excessive deposition of mucin in the dermis that leads to the presentation of skin folds, and in more severe cases the formation of vesicles or blisters. Hyaluronic acid has been identified as the main component of mucin, however the etiopathogenesis, prevention and treatment of this disease have not yet been fully elucidated. This paper reports a 3-year-old Shar pei dog, diagnosed with cutaneous mucinosis. On physical examination, multiple vesicles containing transparent and viscous fluid and hypotrichosis were observed in the ventral region of the neck, armpits, bilateral flank, perianal and in the distal portion of the limbs. In the pelvic limbs there was also the presence of edema. The affected skin was swollen, thickened and negative at Godet's sign. Blood tests, scrapes and skin cytology were performed. Blood tests did not show any 
significant alterations, as well as scraping and skin cytology showed negative results. Based on these results, it was decided to perform a skin biopsy and histopathological analysis. Intense and diffuse myxomatous edema was observed, mainly in the most superficial and perianexal region, with the formation of mucin lakes, confirming the diagnosis. For treatment, prednisolone was prescribed at a dose of $1 \mathrm{mg} / \mathrm{kg}$ every 24 hours, for 7 days, reducing the dose until the drug was discontinued in 30 days. After 21 days of treatment, the patient had complete resolution of the lesions and itching. It was possible to conclude that cutaneous mucinosis is an exclusive dermatopathy of dogs of the Shar pei breed due to the intense genetic selection throughout the breed's history. The impact of high hyaluronic acid synthesis on the phenotype of these dogs is only partially known. In this way, many other sites and systemic effects of hyaluronic acid still need to be understood since this glycosaminoglycan is synthesized by several cells and can be found in various tissues and body fluids with varying concentrations.

Keywords: Hyaluronic acid, dogs, dermatopathy, mucin

\section{Mucinosis cutánea en perro Shar pei: Reporte de un caso}

Resumen. La mucinosis cutánea es una dermatopatía idiopática primaria que se presenta en perros de la raza Shar pei, caracterizada por un depósito excesivo de mucina en la dermis que conduce a la presentación de pliegues cutáneos y, en casos más graves, a la formación de vesículas o ampollas. El ácido hialurónico se ha identificado como el componente principal de la mucina, sin embargo, la etiopatogenia, la prevención y el tratamiento de esta enfermedad aún no se han aclarado por completo. Este artículo informa sobre un perro Shar pei de 3 años de edad, diagnosticado con mucinosis cutánea. En el examen físico, se observaron múltiples vesículas que contenían líquido transparente y viscoso e hipotricosis en la región ventral del cuello, axilas, flanco bilateral, perianal y en la porción distal de las extremidades. En las extremidades pélvicas también había presencia de edema. La piel afectada estaba hinchada, engrosada y negativa ante el signo de Godet. Se realizaron análisis de sangre, raspaduras y citología de la piel. Los análisis de sangre no mostraron alteraciones significativas, así como el raspado y la citología de la piel mostraron resultados negativos. En base a estos resultados, se decidió realizar una biopsia de piel y un análisis histopatológico. Se observó edema mixomatoso intenso y difuso, principalmente en la región más superficial y perianexal, con la formación de lagos de mucina, confirmando el diagnóstico. Para el tratamiento, se prescribió prednisolona a una dosis de $1 \mathrm{mg} / \mathrm{kg}$ cada 24 horas, durante 7 días, reduciendo la dosis hasta que se suspendió el medicamento en 30 días. Después de 21 días de tratamiento, el paciente tenía una resolución completa de las lesiones y picazón. Fue posible concluir que la mucinosis cutánea es una dermatopatía exclusiva de perros de la raza Shar pei debido a la intensa selección genética a lo largo de la historia de la raza. El impacto de la alta síntesis de ácido hialurónico en el fenotipo de estos perros es solo parcialmente conocido. De esta manera, muchos otros sitios y efectos sistémicos del ácido hialurónico aún deben entenderse ya que este glicosaminoglicano es sintetizado por varias células y puede encontrarse en varios tejidos y fluidos corporales con concentraciones variables.

Palabras clave: Ácido hialurónico, perros, dermatopatía, mucina

\section{Introdução}

Entre as raças de cães, o Shar pei possui um fenótipo particular caracterizado por uma pele espessa e enrugada, que lhes confere as típicas dobras cutâneas (Docampo et al., 2011). A apresentação desta característica ocorre devido a uma maior deposição de mucina difusa na derme, definida como mucinose cutânea (MC) (Zanna et al., 2008). A mucina é um componente da matriz extracelular da derme, constituída principalmente por ácido hialurônico (AH) (Rongioletti \& Rebora, 2001).

A MC é considerada uma dermatose relativamente rara em cães, exceto em Shar peis (Bomhard \& Kraft, 1998). De acordo com sua apresentação, pode ser classificada como idiopática ou primária, como 
ocorre nos cães Shar pei, ou secundária a doenças como hipotireoidismo, intertrigo, lúpus eritematosos, doenças neoplásicas (Doliger et al., 1995; Lopez et al., 1999). Os sinais clínicos apresentados com o acúmulo de $\mathrm{AH}$ apresentam-se na forma de espessamento e inchaço da pele, vesículas e bolhas que podem romper e gerar grande deformidade do local afetado (Paterson, 2009; Sischo et al., 1989).

Dentre os diagnósticos diferenciais incluem-se hipotireoidismo, doenças cutâneas autoimunes e imunomediadas (Hnilica \& Patterson, 2017). O diagnóstico definitivo pode ser facilmente confirmado por histopatologia, o qual mostra uma substância pálida e basofílica que desloca as fibras de colágeno causando uma atrofia dérmica variável (Paterson, 2009; Sischo et al., 1989).

As alterações cutâneas se resolvem de forma espontânea na maioria dos cães, porém em alguns casos é necessária a utilização de glicocorticoides para reduzir o acúmulo de mucina (Hnilica \& Patterson, 2017). O impacto dessa alta síntese de AH no fenótipo destes cães é apenas parcialmente conhecido. Muitos outros locais e efeitos sistêmicos do AH ainda precisam ser compreendidos (Zanna et al., 2009). Dessa forma, o objetivo deste trabalho é relatar um caso de mucinose cutânea em um cão da raça Shar pei, contribuindo para seu registro devido à escassez de dados acerca desta enfermidade.

\section{Relato de caso}

Um cão da raça Shar pei, fêmea, três anos de idade, $17,8 \mathrm{~kg}$, castrada, foi atendido na Clínica Escola de Medicina Veterinária da Universidade Tuiuti do Paraná com histórico de prurido generalizado, presença de bolhas e hipotricose em pescoço, axilas, flanco e membros, com início há 8 meses. Anteriormente, já havia apresentado otite recorrente, puliciose, prurido e lambedura de membros, onde foi realizado o tratamento com produtos tópicos e corticoides por via oral, com melhora significativa dos sinais enquanto o tratamento estava sendo realizado. Há 3 dias estava sendo medicada com $0,7 \mathrm{mg}$ de anti-histamínico a base de clemastina, a cada 12 horas e banhos com xampu de clorexidina a cada 15 dias, apresentando melhora do prurido, mas sem melhora das lesões.

Para avaliar a gravidade do prurido/lambedura utilizou-se uma escala de 1 a 10, onde a nota 1 é para quando não há sinais de prurido, e nota 10 para casos em que o prurido é grave. A nota atribuída à paciente foi 10 e não havia sazonalidade, o prurido ocorria durante o ano todo. A puliciose era tratada com spinosad na dose de $30 \mathrm{mg} / \mathrm{kg}$ por via oral mensalmente. Havia um contactante canino sem sinais clínicos e o paciente possuía acesso a rua, acompanhado, diariamente. As vacinas e o vermífugo estavam atualizados.

Ao exame físico foram observadas múltiplas vesículas contendo fluido transparente e viscoso e hipotricose em região ventral do pescoço, axilas, flanco bilateral, perianal e na porção distal dos membros (Figura 1). Nos membros pélvicos havia também a presença de edema (Figura 2). A pele acometida apresentava-se inchada, espessada e negativa ao sinal de Godet.

Foram realizados exame de sangue, raspado e citologia de pele. Os exames de sangue não apresentaram alterações significativas, assim como o raspado e a citologia de pele apresentaram resultados negativos para ácaros e infecção respectivamente. Mediante estes resultados optou-se por realizar biópsia de pele e análise histopatológica. Foi observado epiderme com ortoqueratose em trançado de cesto leve. Na derme, edema mixomatoso intenso e difuso, principalmente na região mais superficial e perianexal, com formação de lagos de mucina. A maioria dos folículos pilosos estava ativa, e as glândulas sebáceas e apócrinas não apresentaram alterações patológicas. Ainda, não foram evidenciados parasitas foliculares e sinais de transformação ou infiltração neoplásica. Foi possível concluir que havia mucinose cutânea.

Para o tratamento foi prescrito prednisolona na dose de $1 \mathrm{mg} / \mathrm{kg}$ a cada 24 horas, durante sete dias. Após, $0,5 \mathrm{mg} / \mathrm{kg}$ a cada 24 horas, por sete dias. Na terceira semana $0,5 \mathrm{mg} / \mathrm{kg}$ a cada 48 horas, por mais 7 dias. Na quarta semana $0,5 \mathrm{mg} / \mathrm{kg}$ a cada 72 horas, por mais 7 dias e suspensão do uso. Foram prescritos também banhos semanais com xampu a base de gliconutrientes de soja, vitamina F, manteiga de karité e fitoesfingosina. Após 21 dias de tratamento o paciente apresentou resolução total das lesões e do prurido. 


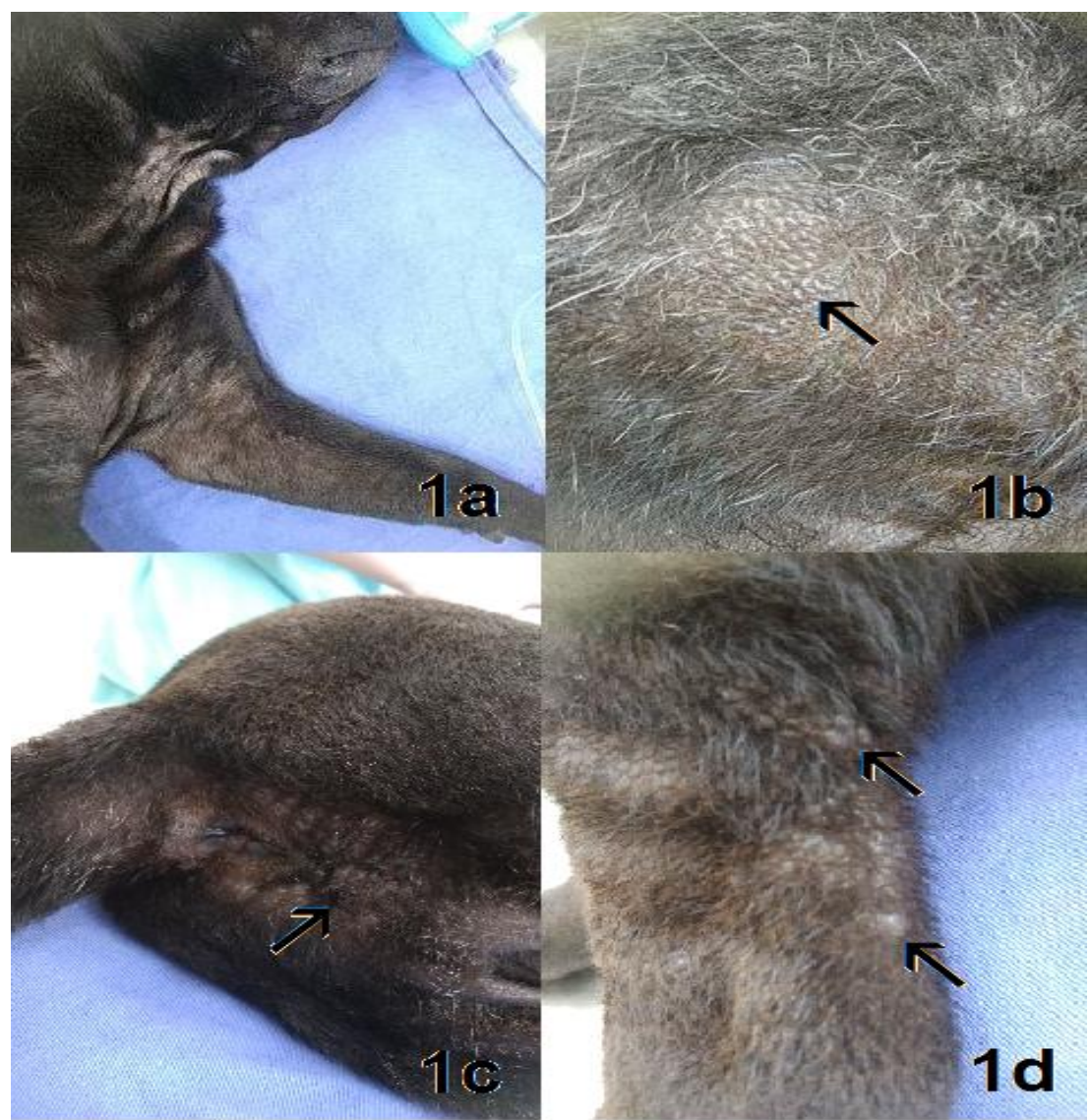

Figura 1. Exame físico de cão da raça Shar pei com mucinose cutânea. Legenda: Múltiplas vesículas contendo fluido transparente e viscoso (setas) e hipotricose em região distal de pescoço e nas axilas (1a), lateral direita de flanco (1b), perianal (1c) e membro pélvico esquerdo (1d).

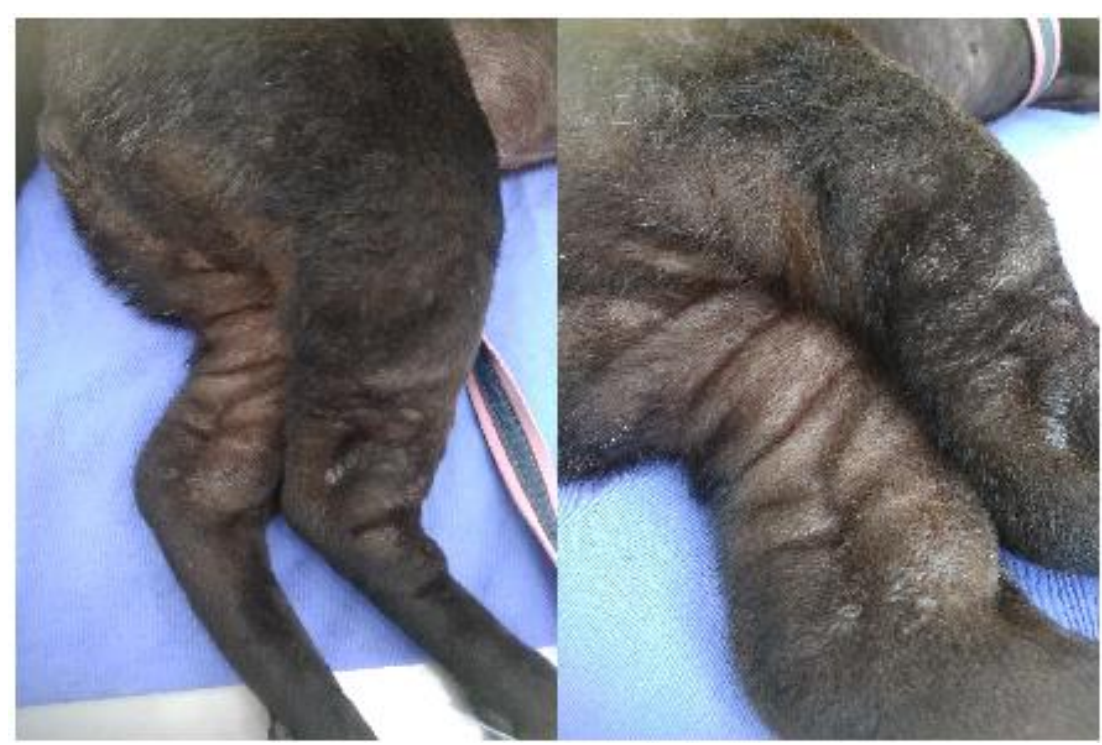

Figura 2. Edema de membros pélvicos em cão da raça Shar pei com mucinose cutânea.

\section{Discussão}

Algumas pesquisas foram realizadas a fim de compreender, caracterizar e explicar por que o Shar pei tem este fenótipo característico (Welle et al., 1999; Zanna et al., 2008; Zanna et al., 2009). A intensa seleção artificial para características morfológicas resultou em reduções de fatores genéticos e uma grande quantidade de mutações deletérias (Marsden et al., 2016). O Shar pei é uma das raças de cães que mais apresentam doenças de origem genética, o que poderia ser explicado devido à história da raça, 
uma vez que a maioria dos cães atuais são descendentes de um pequeno núcleo fundador (Díaz, 2015). O caso relatado abordou um cão da raça Shar pei, fêmea, com 3 anos de idade, com histórico de prurido generalizado, presença de bolhas e hipotricose em pescoço, axilas, flanco e membros, com início há 8 meses. Anteriormente, o paciente já havia apresentado otite recorrente, puliciose, prurido e lambedura de membros, onde foi realizado o tratamento com produtos tópicos e corticoides por via oral, com melhora significativa dos sinais enquanto o tratamento estava sendo realizado. Segundo Bell et al. (2012), o Shar pei possui doenças dermatológicas de caráter predisponente, sendo as principais o pênfigo foliáceo, demodiciose, a febre crônica do Shar pei e a mucinose cutânea.

A excessiva deposição de mucina na derme leva a apresentação de dobras cutâneas, e em casos mais graves pode apresentar a forma vesicular caracterizada por vesículas ou bolhas. Essa condição foi definida como mucinose cutânea idiopática primária, presumivelmente de origem hereditária (Bomhard \& Kraft, 1998). O AH foi identificado como o principal componente da mucina depositada na derme. Este glicosaminoglicano $(\mathrm{AH})$ por sua vez, é sintetizado por vários tipos de células, incluindo fibroblastos, queratinócitos e células endoteliais, e pode ser encontrado em vários tecidos e fluidos corporais com concentrações variadas (Zanna et al., 2009). Além da derme, os níveis séricos de AH em cães com mucinose cutânea também são altos. Isto provavelmente é uma consequência da drenagem linfática do AH sintetizado na derme (Docampo et al., 2011). No entanto, a etiopatogenia, prevenção e tratamento desta dermatopatia ainda não foram totalmente elucidados (Zanna et al., 2008).

Lesões de caráter vesicular distribuídas em região periocular, membros anteriores e posteriores são alguns sinais clínicos apresentados em animais com mucinose cutânea (Rongioletti \& Rebora, 2001). Linfedema também pode ocorrer em membros devido à obstrução dos vasos linfáticos pelo $\mathrm{AH}, \mathrm{o}$ qual impossibilita o retorno do líquido linfático de volta ao sistema vascular (Díaz, 2015). Neste relato foram observadas múltiplas vesículas contendo fluido transparente e viscoso e hipotricose em região ventral do pescoço, axilas, flanco bilateral, perianal e na porção distal dos membros. Além disso, havia também a presença de edema em membros pélvicos e a pele acometida apresentava-se inchada, espessada e negativa ao sinal de Godet.

O diagnóstico é baseado no histórico, sinais clínicos do paciente, exclusão dos diagnósticos diferenciais, citologia das vesículas e confirmação através de exame histopatológico (Hnilica \& Patterson, 2017). Neste caso foram realizados exame de sangue, raspado e citologia de pele. Os exames de sangue não apresentaram alterações significativas, assim como o raspado e a citologia de pele apresentaram resultados negativos para ácaros e infecção respectivamente, descartando os diagnósticos diferenciais como demodiciose, intertrigo e hipotireoidismo. Mediante estes resultados optou-se por realizar biópsia de pele e análise histopatológica. Na derme foi observado edema mixomatoso intenso e difuso, principalmente na região mais superficial e perianexal, com formação de lagos de mucina. Em estudos anteriores, a análise histopatológica foi caracterizada pela presença de uma substância cinza pálida, sugestivo de mucina, o que resultou em uma separação acentuada de fibras dérmicas de colágeno. A deposição desta substância foi mais pronunciada na derme superior e levou à formação de lagos ou vesículas subepidérmicas (Zanna et al., 2008). Ainda, não foram evidenciados parasitas foliculares e sinais de transformação ou infiltração neoplásica, sendo possível concluir que havia mucinose cutânea.

As alterações cutâneas se resolvem de forma espontânea na maioria dos cães. Nos casos mais importantes, o tratamento com doses imunossupressoras de prednisolona pode reduzir o acúmulo de mucina (Hnilica \& Patterson, 2017). Para o tratamento foi prescrito prednisolona na dose de $1 \mathrm{mg} / \mathrm{kg}$ a cada 24 horas, durante sete dias, reduzindo a dose até a suspensão do medicamento em 30 dias. Após 21 dias de tratamento o paciente apresentou resolução total das lesões e do prurido. Durante anos, os casos graves de mucinose cutânea em cães Shar pei foram tratados com corticosteroides com respostas positivas a este protocolo (Miller et al., 2013; Bomhard \& Kraft, 1998). Estes resultados mostram que esta terapia é eficaz porque o gene HAS2 tem um papel central na patogênese da mucinose cutânea, e a expressão deste gene é fortemente suprimida por glicocorticoides (Docampo et al., 2011; Gebhardt et al., 2010; Stuhlmeier \& Pollaschek, 2004). 


\section{Conclusão}

Foi possível concluir que a mucinose cutânea é uma dermatopatia primaria hereditária exclusiva de cães da raça Shar pei devido à intensa seleção genética ao longo da história da raça. O impacto da alta síntese de HA no fenótipo de cães Shar pei é apenas parcialmente conhecido. Deste modo, muitos outros locais e efeitos sistêmicos da $\mathrm{AH}$ ainda precisam ser compreendidos já que este glicosaminoglicano é sintetizado por diversas células e pode ser encontrado em vários tecidos e fluidos corporais com concentrações variadas.

\section{Referências}

Bell, J., Cavanagh, K., Tilley, L., \& Smith, F. W. K. (2012). Veterinary medical guide to dog and cat breeds. CRC Press.

Bomhard von D., Kraft W. (1998). Idiopathic mucinosis cutis in Chinese Shar pei dogs: Epidemiology, clinical features, histopathologic findings and treatment. Tierarztl Prax Ausg Klientiere Heimtiere; 26: 189-196.

Díaz, V. L. M. (2015). Genetic background of hereditary cutaneous hyaluronosis and familial shar pei fever. Universitat Autònoma de Barcelona,.

Docampo, M. J., Zanna, G., Fondevila, D., Cabrera, J., López-Iglesias, C., Carvalho, A., Cerrato, S., Ferrer, L., \& Bassols, A. (2011). Increased HAS2-driven hyaluronic acid synthesis in shar-pei dogs with hereditary cutaneous hyaluronosis (mucinosis). Veterinary Dermatology, 22(6), 535-545. https://doi.org/10.1111/j.1365-3164.2011.00986.x.

Doliger, S., Delverdier, M., More, J., Longeart, L., Regnier, A., \& Magnol, J. P. (1995). Histochemical study of cutaneous mucins in hypothyroid dogs. Veterinary Pathology, 32(6), 628-634. https://doi.org/10.1177/030098589503200603.

Gebhardt, C., Averbeck, M., Diedenhofen, N., Willenberg, A., Anderegg, U., Sleeman, J. P., \& Simon, J. C. (2010). Dermal hyaluronan is rapidly reduced by topical treatment with glucocorticoids. Journal of Investigative Dermatology, 130(1), 141-149. https://doi.org/10.1038/jid.2009.210.

Hnilica, K. A., \& Patterson, A. P. (2017). Autoimmune and immune-mediated skin disorders. In K. A. Hnilica \& P. A.P. (Eds.), Small animal dermatology: a color atlas and therapeutic guide. Elsevier.

Lopez, A., Spracklin, D., McConkey, S., \& Hanna, P. (1999). Cutaneous mucinosis and mastocytosis in a shar-pei. The Canadian Veterinary Journal, 40(12), 881-883.

Marsden, C. D., Ortega-Del Vecchyo, D., O’Brien, D. P., Taylor, J. F., Ramirez, O., Vilà, C., MarquesBonet, T., Schnabel, R. D., Wayne, R. K., \& Lohmueller, K. E. (2016). Bottlenecks and selective sweeps during domestication have increased deleterious genetic variation in dogs. Proceedings of the National Academy of Sciences, 113(1), 152-157. https://doi.org/10.1073/pnas.1512501113.

Miller, W. H., Griffin, C. E., Campbell, K. L., \& Muller, G. H. (2013). Muller and Kirk's Small Animal Dermatology. Elsevier Health Sciences.

Paterson, S. (2009). Manual of skin diseases of the dog and cat. John Wiley \& Sons.

Rongioletti, F., \& Rebora, A. (2001). Cutaneous mucinoses: microscopic criteria for diagnosis. The American Journal of Dermatopathology, 23(3), 257-267. https://doi.org/10.1097/00000372200106000-00022.

Sischo, W. M., Ihrke, P. J., \& Franti, C. E. (1989). Regional distribution of ten common skin diseases in dogs. Journal of the American Veterinary Medical Association, 195(6), 752-756.

Stuhlmeier, K. M., \& Pollaschek, C. (2004). Glucocorticoids inhibit induced and non-induced mRNA accumulation of genes encoding hyaluronan synthases (HAS): hydrocortisone inhibits HAS1 activation by blocking the p38 mitogen-activated protein kinase signalling pathway. Rheumatology, 43(2), 164-169. https://doi.org/10.1093/rheumatology/keh014.

Welle, M., Grimm, S., Suter, M., \& Von Tscharner, C. (1999). Mast cell density and subtypes in the skin of Shar Pei dogs with cutaneous mucinosis. Journal of Veterinary Medicine Series A, 46(5), 309-316. https://doi.org/10.1046/j.1439-0442.1999.00220.x.

Zanna, G, Fondevila, D., Bardagi, M., Docampo, M. J., Bassols, A., \& Ferrer, L. (2008). Cutaneous 
mucinosis in shar-pei dogs is due to hyaluronic acid deposition and is associated with high levels of hyaluronic acid in serum. Veterinary Dermatology, 19(5), 314-318. https://doi.org/10.1111/j.13653164.2008.00703.x.

Zanna, Giordana, Docampo, M. J., Fondevila, D., Bardagí, M., Bassols, A., \& Ferrer, L. (2009). Hereditary cutaneous mucinosis in shar pei dogs is associated with increased hyaluronan synthase-2 mRNA transcription by cultured dermal fibroblasts. Veterinary Dermatology, 20(5-6), 377-382. https://doi.org/10.1111/j.1365-3164.2009.00799.x.

\section{Histórico do artigo}

Recebido: 15 de dezembro de 2020. Aprovado: 5 de janeiro de 2021.

Disponível online: 13 de abril de 2021 .
Licenciamento: Este artigo é publicado na modalidade Acesso Aberto sob a licença Creative Commons Atribuição 4.0 (CC-BY 4.0), a qual permite uso irrestrito, distribuição, reprodução em qualquer meio, desde que o autor e a fonte sejam devidamente creditados. 